\title{
Accumulative Effect of Soil Organic Carbon and Nitrogen in Water-Stable Aggregates and Soil Stability Characteristics of Robinia pseudoacacia Plantation in the Loess Hilly-Gully Region
}

\author{
Jiao Sun ${ }^{1,2}$, Junfeng $\mathrm{Li}^{3 *}$, Gaihe Yang4, Wenfang Hao ${ }^{{ }^{*}}$ \\ ${ }^{1}$ College of Life Science, Northwest Agriculture and Forest University, Yangling, Shaanxi, China \\ ${ }^{2}$ Institute of Agricultural Resources and Environment, Ningxia Academy of Agriculture and Forestry Sciences, Yinchuan, Ningxia, China \\ ${ }^{3}$ College of Water Conservancy and Architectural Engineering, Shihezi University, Shihezi, Xinjiang, China \\ ${ }^{4}$ College of Agriculture, Northwest Agriculture and Forest University, Yangling, Shaanxi, China \\ Email: *haowenfang@nwsuaf.edu.cn, *ljfshz@126.com
}

How to cite this paper: Sun, J., Li, J.F., Yang, G.H. and Hao, W.F. (2016) Accumulative Effect of Soil Organic Carbon and Nitrogen in Water-Stable Aggregates and Soil Stability Characteristics of Robinia pseudoacacia Plantation in the Loess Hilly-Gully Region. Open Journal of Soil Science, 6, 204-221.

http://dx.doi.org/10.4236/ojss.2016.612019

Received: October 28, 2016

Accepted: December 5, 2016

Published: December 8, 2016

Copyright $\odot 2016$ by author(s) and Scientific Research Publishing Inc. This work is licensed under the Creative Commons Attribution International License (CC BY 4.0).

http://creativecommons.org/licenses/by/4.0/

\section{Abstract}

Soil water-stable aggregates (WSAs) are the basic unit of soil constitution and can contribute to remaining the stable soil constitution. The objective of this study was to clarify the distribution and stability of WSAs and the soil organic carbon (SOC), the total nitrogen (TN), and the total phosphorus (TP) concentrations in $0-20 \mathrm{~cm}$ and 20 - $40 \mathrm{~cm}$ soil layers under the different ages of Robinia pseudoacacia plantations. The 20, 25, 40, and 50 years-old Robinia pseudoacacia plantations were selected. Stepwise regression analysis showed that $>5 \mathrm{~mm}$ and $1-2 \mathrm{~mm}$ WSAs, SOC concentration in 2 - $5 \mathrm{~mm}$ WSAs, and TN and TP concentrations in $<0.25 \mathrm{~mm}$ WSAs were dominant independent variables affecting aggregate stability and that SOC in $0.25-0.5$ mm WSAs, TN in $<0.25 \mathrm{~mm}$ and $1-2 \mathrm{~mm}$ WSAs and TP in 2 - $5 \mathrm{~mm}$ WSAs were dominant independent variables affecting SOC, TN, and TP concentrations in bulk soils.

\section{Keywords}

Soil Water-Stable Aggregate, Robinia pseudoacacia Plantation, Soil Nutrient

\section{Introduction}

Soil aggregates are the basic units of soil constitution and help keep it stable. They are also the determinant factor of soil fertility [1]. Soil structure and aggregate stability are the keys to soil function and the ability of soil to support plant growth. Stable soil constitution is effective in maintaining the balance among soil ventilation, water retention, 
and the release and retention of nutrients [2]. Water-stable aggregates (WSAs) are especially important for determining soil fertility [3]. The form and stability of SOC, TN, and TP concents can differ in aggregates of different sizes and these affect the evolution of soil fertility [4]. In this way, the concentration of SOC, TN, and TP in aggregates plays a key role in improving soil fertility. In the present study, SOC and TN concents are dominant reserved in WSAs $0.25-2 \mathrm{~mm}$ [5]. The MWD was positively correlated with TN and TP concents in soil macro-aggregates [6]. The distribution of TP in WSAs of different sizes was greatly affected by the soil acid-base-properties; there is more phosphorus in smaller aggregates in acidic soil than in basic soil [7].

Human activity has affected Chinese ecosystems for millennia [8]. In last century, fragmentation and degradation of ecological environments have accelerated due to increasing population pressure. The effects of human activity in loess hilly areas can be attributed to continuous and widespread stress, such as over-grazing and large-scale monoculture (wheat and maize) [9]. The Chinese loess hilly areas are some of the most severely eroded regions in the world [10]. To prevent further deterioration of natural ecosystems, the Chinese government launched the Grain for Green Project, focusing on the rehabilitation and recovery of damaged ecosystems [11].

Robinia pseudoacacia was introduced for the Grain for Green Project from its native range in south-eastern North America to other areas of North America and in temperate South America, northern and southern Africa, temperate Asia, Europe, Australia and New Zealand [12]. Robinia pseudoacacia is one of the most widely-planted tree species in the world after several Eucalyptus and Poplar species [13], and it is cultivated worldwide because it has a strong root system, grows rapidly with a high survival rate and can live under rough conditions [14]. Studies have shown that plantation age affects a series of changes in the physical and chemical properties of the soil [15]. Increases in soil SOC and TN concentrations in measured soils can strengthen soil aggregate stability, improve soil structure, and promote the formation of macro-aggregates. Many researches of the soil fertility of Robinia pseudoacacia plantations on loess hilly-gully areas have been conducted. Although these have mainly focused on the differences in nutrient concentrations over soil latitude [16] and plantation age [17], few studies have been done on the relationship between the distribution of WSAs and changes in SOC, TN, and TP concentrations in WSAs.

The objectives of this study were to investigate the distribution and stability of WSAs and SOC, TN, and TP concentrations in WSAs in $0-20 \mathrm{~cm}$ and $20-40 \mathrm{~cm}$ soil layers in Robinia pseudoacacia plantations of different ages in China's loess hilly region. The manner by which the Robinia pseudoacacia plantations of different ages influenced soil SOC and TN accumulation in WSAs was also determined.

\section{Materials and Methods}

\subsection{Study Site}

The study was conducted in the Wuliwan catchment (36 51'29.082" $-36^{\circ} 52^{\prime} 14.605^{\prime \prime} \mathrm{N}$, $109^{\circ} 19^{\prime} 05.599^{\prime \prime}-109^{\circ} 21^{\prime} 8.619^{\prime E}$ ), which is located in Ansai County in China's Shaanxi 
Province (Figure 1). This is a typical loess hilly area whose elevation ranges from $997 \mathrm{~m}$ to $1731 \mathrm{~m}$. This area has a sub-arid climate characterized by heavy seasonal rainfall with periodic floods and droughts. The average annual precipitation is $535 \mathrm{~mm}$, and the area has distinct wet and dry seasons. The rainy season lasts from July to September. The aridity index is 1.48 and the mean annual temperature is $8.8^{\circ} \mathrm{C}$. On average, there are about 157 frost-free days and annual radiation can reach up to $552.6 \mathrm{KJ} \cdot \mathrm{cm}^{-2}$. Geomorphically, this area is a typical hilly region, with a loessial soil texture developed from loess basis. Sand $(0.05-2 \mathrm{~mm})$ and silt $(0.002-0.05 \mathrm{~mm})$ account for approximately $29.22 \%$ and $63.56 \%$, respectively, at a soil depth of $0-20 \mathrm{~cm}$. This type of soil is barren and highly susceptible to erosion. Natural vegetation types vary from northwest to southeast from arid desert to steppe to broad-leaved deciduous forest. Constructive species in this area include Platycladus orientalis, Caragana microphylla, and Bothriochloa ischaemum et al. [18].

The major type of agricultural land use in the loess hilly region is slope cropland. The main crops grown at these sites were millet (Setariaitalica) and soybean (Glycine max) rotation, and no irrigation is provided during the growing season (crops depend on rainfall). One crop is grown each year, and fertilizer is applied (mainly manure). Since the launch of the Grain for Green Project, slope cropland is replanted with mainly Robinia pseudoacacia plantations in this catchment to control soil erosion. Concerning the soil basis and location of Robinia pseudoacacia plantations, 20, 25, 40, and 50 years-old Robinia pseudoacacia plantations from the neighboring areas were selected and studied. Age of plantations and time of cropland were obtained from interviews with local farmers and they were contrasted with records registered in the An'sai Eco-
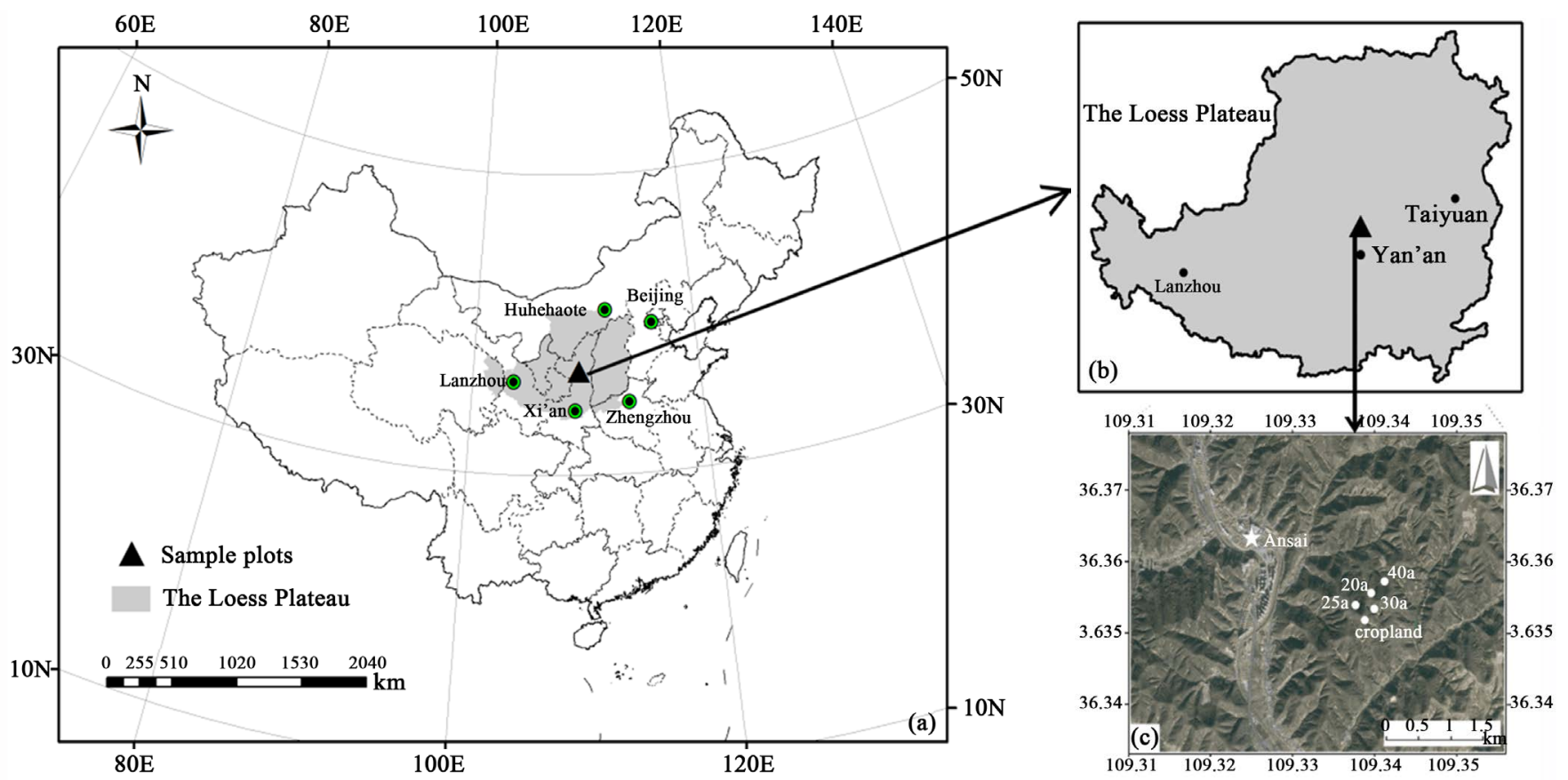

Figure 1. Map of research region (Ansai county, Shaanxi province, China). 
logical Experimental Station of Soil and Water Conservation. Basic information regarding the four sites is given in Table 1.

\subsection{Soil Sampling}

Soil samples were collected at $0-20 \mathrm{~cm}$ and $20-40 \mathrm{~cm}$ depths in September 2013. An area of $60 \times 20 \mathrm{~m}^{2}$ was delineated at each site. Within this area, three $20 \times 20 \mathrm{~m}^{2}$ plots were selected for sampling. Two undisturbed soil samples were collected from each plot. Twelve soil samples with dimensions of $20 \times 15 \times 15 \mathrm{~cm}$ were obtained using an aluminum box at each site. Then every four soil samples of each plot were composited by depth. The whole of composite samples were gently broken along planes of weakness, passed through a $10 \mathrm{~mm}$ sieve, and then air-dried.

\subsection{Laboratory Methods}

WSAs were selected using a modified version of Yoder's method with a set of $5 \mathrm{~mm}, 2$ $\mathrm{mm}, 1 \mathrm{~mm}, 0.5 \mathrm{~mm}, 0.25 \mathrm{~mm}$ sieves [19]. The sieve set was immersed in distilled water for $30 \mathrm{~min}$, resulting in slaking at room temperature. After immersion, the soil samples were oscillated for $3 \mathrm{~min}$ at a displacement of approximately $4 \mathrm{~cm}$ at 37 rounds per minute. All WSAs were collected, air-dried at room temperature, and then weighed and stored until analysis of SOC, TN, and TP concentration. Composite bulk soil samples were also air dried at room temperature, passed through a $0.25 \mathrm{~mm}$ diameter sieve and stored at room temperature until analysis of SOC, TN, and TP concentrations. SOC in the bulk soil and WSAs was determined using a TOC analyzer after treatment with the wet combustion method with $\mathrm{K}_{2} \mathrm{Cr}_{2} \mathrm{O}_{7}$ at $180^{\circ} \mathrm{C}$. TN in the bulk soil and WSAs was determined using a flow analyzer procedure after treatment with $\mathrm{HClO}_{4}-\mathrm{H}_{2} \mathrm{SO}_{4}$. TP in the bulk soil and WSAs was determined following $\mathrm{H}_{2} \mathrm{SO}_{4}-\mathrm{HClO}_{4}$ digestion [20]. The basic physical and chemical properties of tested soil samples are shown in Table 2.

Mean weight diameter (MWD) and WSAs $>0.25 \mathrm{~mm}\left(R_{0.25}\right)$ were used to signifying the aggregate stability. The $R_{0.25}$ and MWD were calculated as follows [9] [21].

Table 1. General status of sampling plots

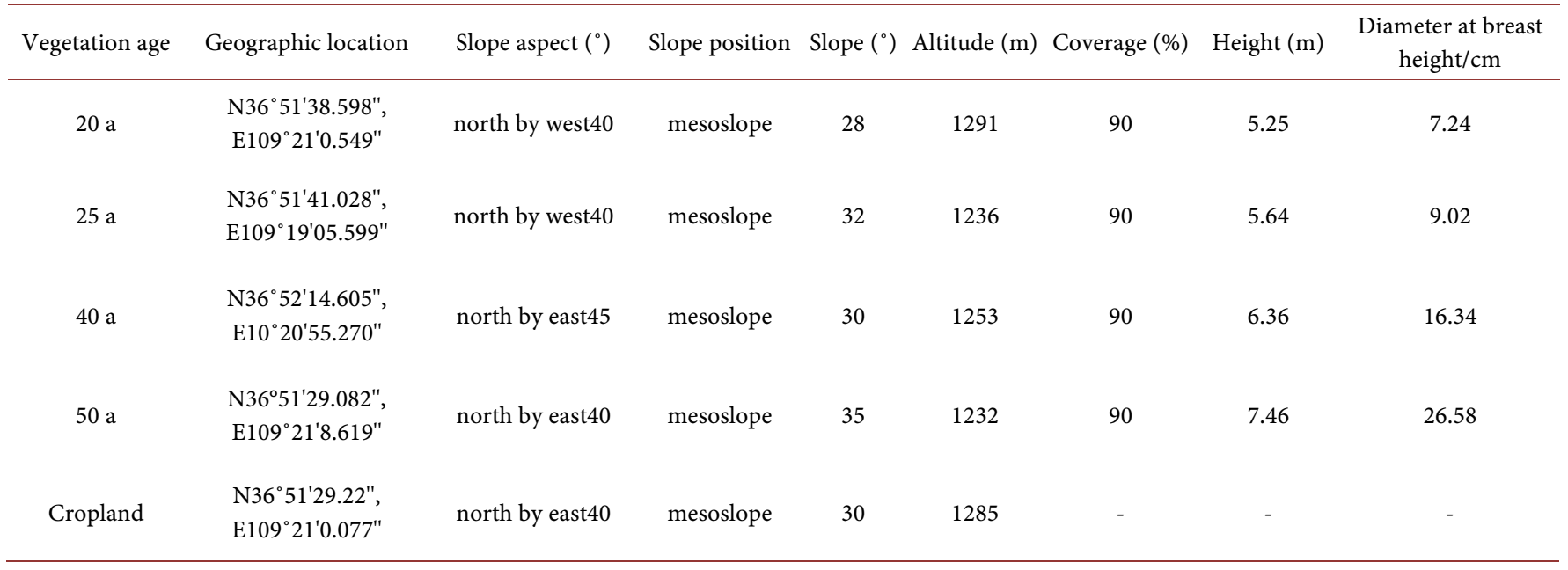


Table 2. Basic physical and chemical properties of tasted soils.

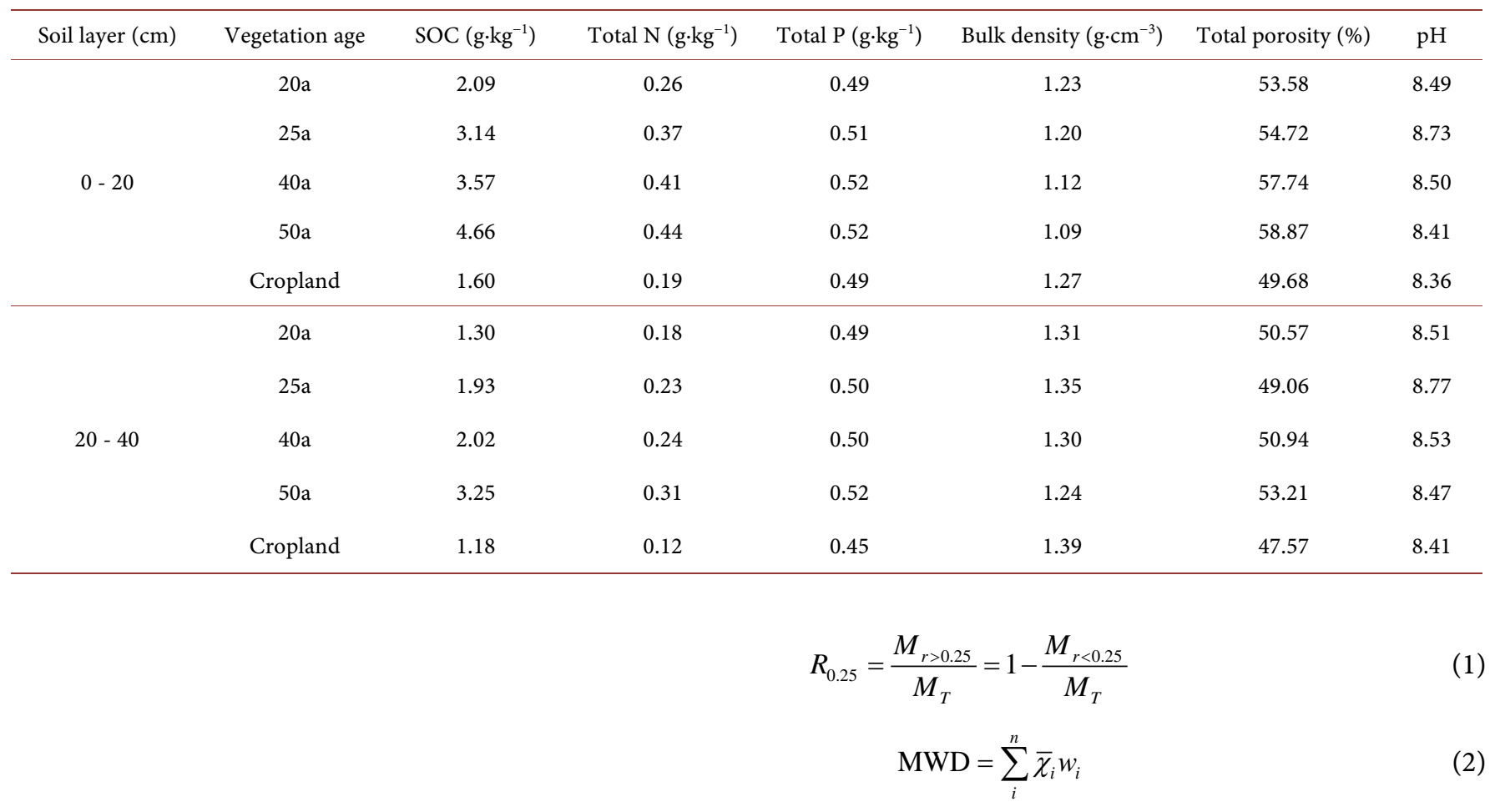

Here, $M_{r>0.25}$ is the mass of WSAs $>0.25 \mathrm{~mm}, M_{T}$ is mass of all size fractions, $\bar{\chi}_{i}$ is the mean diameter of size fraction $i(\mathrm{~mm})$ and $\omega_{i}$ is the proportion of the size fraction $\mathrm{i}$ in relation to the total sample weight. Three replicates were performed per sample for a total of nine measurements per depth per site.

If the distribution of WSAs and the SOC, TN, and TP concentration are known, it is possible to calculate the contribution rate of WSAs as follows: contribution rate of WSAs $(\%)=$ distribution proportion of each aggregate diameter $\times$ soil aggregate nutrient content/soil nutrient content [22].

\subsection{Statistical Analysis}

All statistical analyses were performed using SPSS (Statistical Package for the Social Sciences) 19.0 and Excel 2003. Significant differences were determined using a one-way analysis of variance followed by a least significant difference (LSD) test at $P \leq 0.05$. The relationships among the measured soil attributes were determined using stepwise multiple regression analysis.

\section{Results}

\subsection{Distribution Characteristics of Soil Aggregate Fractions for Robinia pseudoacacia Plantations of Different Ages}

The results of analysis of the distribution and stability of WSAs at Robinia pseudoacacia plantations of different ages are shown in Table 3 for the $0-20 \mathrm{~cm}$ and $20-40 \mathrm{~cm}$ soil layers. With increasing age, the proportion of WSAs $>5 \mathrm{~mm}$ first tended to increase, 
Table 3. Composition of soil water-stable aggregates.

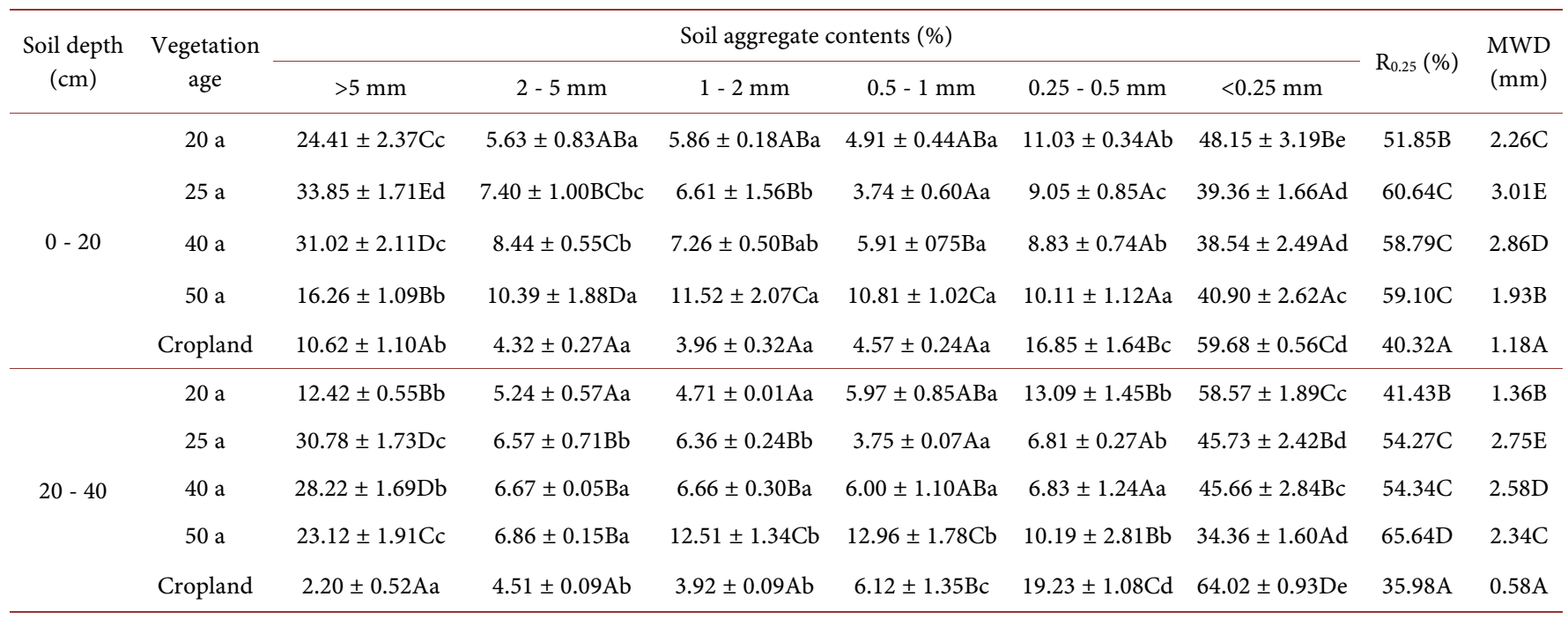

Note: Different small letters in the same row indicate significant differences among aggregates of different sizes at the 0.05 level; different capital letters in the same column indicate significant differences among aggregates of the same size in forests of different ages at the 0.05 level. The same notation is used in subsequent tables.

then decrease. The highest proportion of WSAs $>5 \mathrm{~mm}$ was observed in $25 \mathrm{a}$, the sum accounted for $33.85 \%$ at $0-20 \mathrm{~cm}$ soil depths and $30.78 \%$ at $20-40$ soil depths. At 0 $20 \mathrm{~cm}$ soil layers, the proportion of WSAs $>0.25 \mathrm{~mm}$ was significantly lower $(P<0.05)$ in cropland than in Robinia pseudoacacia plantations. The proportion of WSAs $>0.25$ $\mathrm{mm}$ in 20 a was significantly lower $(P<0.05)$ than in the 25 a, 40 a, and 50 a samples, but no significant difference ( $P>0.05)$ was observed among 25 a, 40 a, and 50 a samples with respect to WSAs $>0.25 \mathrm{~mm}$. At $20-40 \mathrm{~cm}$ soil depth, the proportion of WSAs $>0.25 \mathrm{~mm}$ presented the trend of continuous increasing along with plantation ages. The highest proportion of WSA $>0.25 \mathrm{~mm}$ was observed in $50 \mathrm{a}$, accounting for $65.64 \%$. The variation trend of all size fraction WSAs at $0-20 \mathrm{~cm}$ and $20-40 \mathrm{~cm}$ soil layers were similar. The proportions of WSA $>5 \mathrm{~mm}$ and $>0.25 \mathrm{~mm}$ in cropland, 20 a, $25 \mathrm{a}$, and 50 a were higher at the $0-20 \mathrm{~cm}$ soil layers than at $20-40 \mathrm{~cm}$. But the opposite was true in 50 a samples.

The main proportion of WSAs in Robinia pseudoacacia plantations was always $>5$ $\mathrm{mm}$ and $<0.25 \mathrm{~mm}$ fraction (Table 3), and the sum of these fractions accounted for between $55 \%$ and $76 \%$ of the total weight. The middle proportion of WSAs $0.25-5 \mathrm{~mm}$ accounted for between $4 \%$ and $13 \%$ of the total weight.

MWD is a common measuring index used for the distribution condition of WSAs. The increase in macro-aggregates caused a significant increase $(P<0.05)$ in the MWD (Table 3). MWD values in Robinia pseudoacacia plantations between $1.35 \mathrm{~mm}$ and $3.01 \mathrm{~mm}$. At the $0-20 \mathrm{~cm}$ soil layers, the MWD values appeared in the following order from highest to lowest: $25 \mathrm{a}>40 \mathrm{a}>20 \mathrm{a}>50 \mathrm{a}>$ cropland. The MWD values at the 0 $20 \mathrm{~cm}$ soil layers were higher than the corresponding MWD values from the $20-40 \mathrm{~cm}$ soil layers (but not for $50 \mathrm{a}$ ). At the $20-40 \mathrm{~cm}$ soil layers, the MWD value of 50 a was significantly greater $(P<0.05)$ than that of $20 \mathrm{a}$. The MWD values of cropland, $25 \mathrm{a}$, and 40 a MWD values appeared in the same order as the $0-20 \mathrm{~cm}$ soil layers. 


\subsection{Distribution of Soil Organic Carbon, Total Nitrogen, and Total Phosphorus for Robinia pseudoacacia Plantations of Different Ages}

\subsubsection{Concentration of Organic Carbon, Total Nitrogen, and Total Phosphorus in Soil Water-Stable Aggregates}

The concentrations of organic carbon, total nitrogen, and total phosphorus in WSAs of Robinia pseudoacacia plantations of different ages at $0-20 \mathrm{~cm}$ and $20-40 \mathrm{~cm}$ soil layers are shown in Figures 2-4.

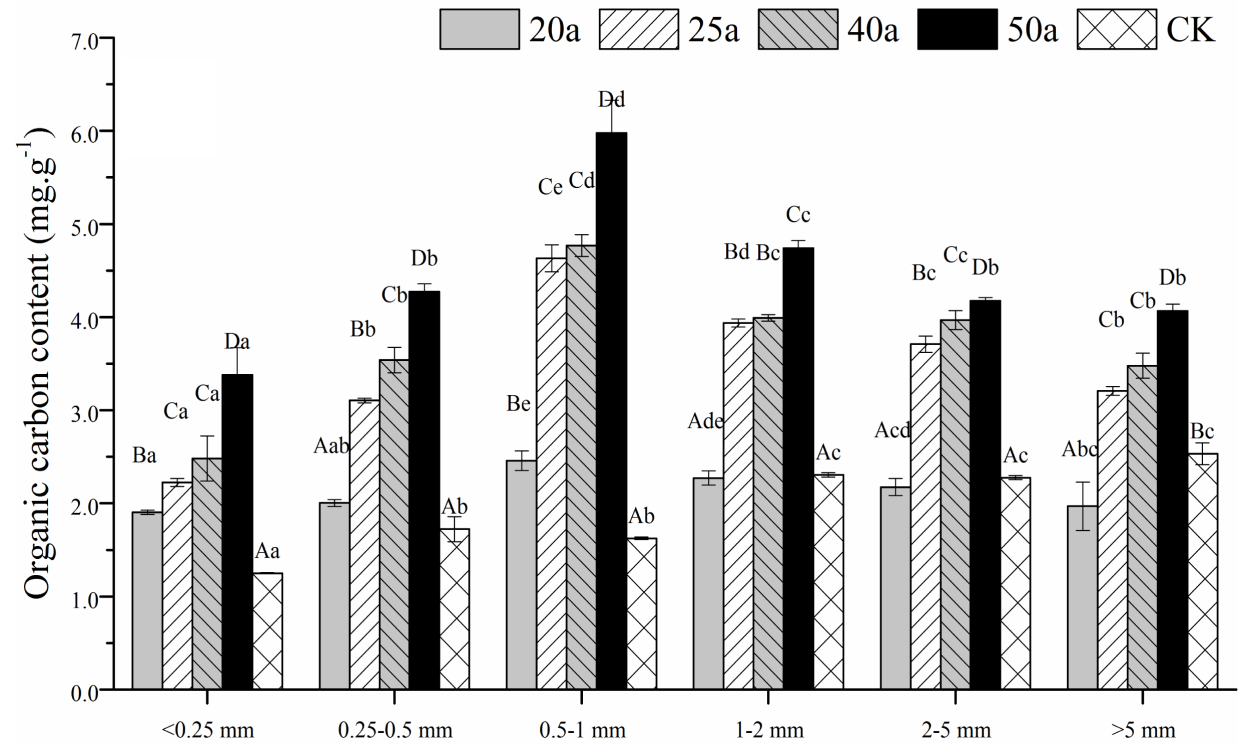

(a)

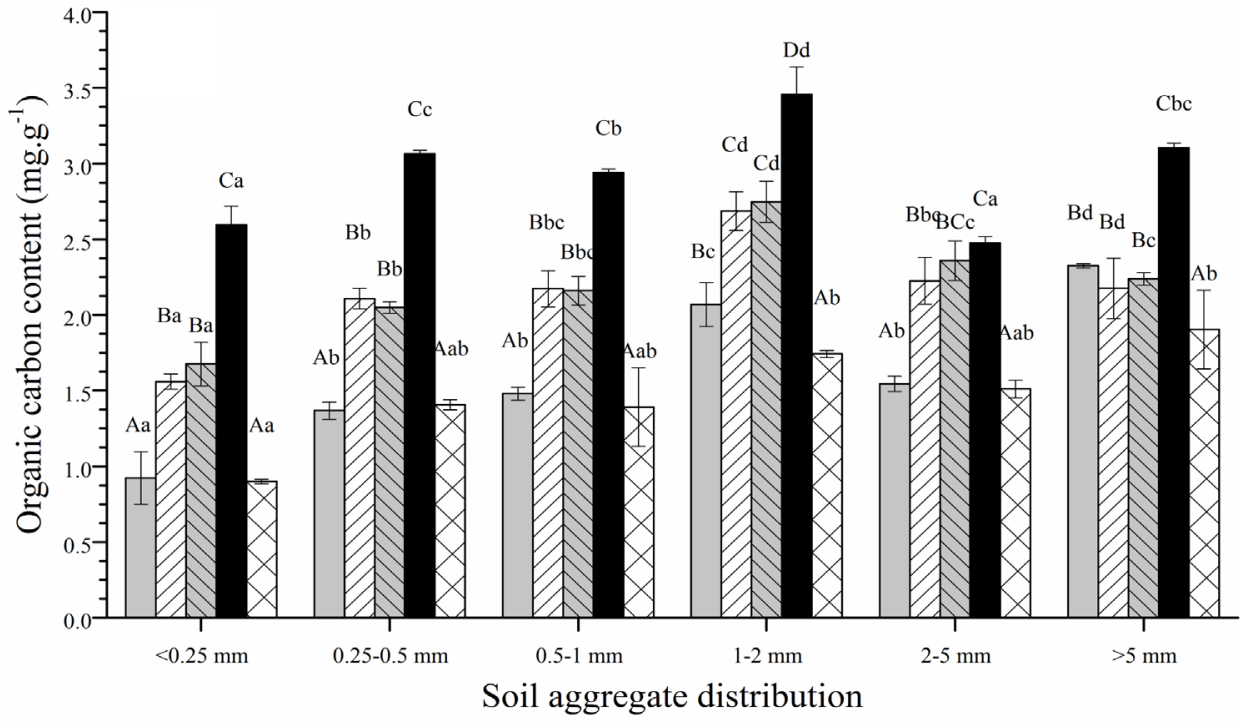

(b)

Figure 2. Concentration of organic carbon in soil water-stable aggregates. Note: Different small letters indicate significant differences among aggregates of different sizes at the 0.05 level; different capital letters indicate significant differences among aggregates of the same size in forests of different ages at the 0.05 level. The same notation is used in subsequent figures. 


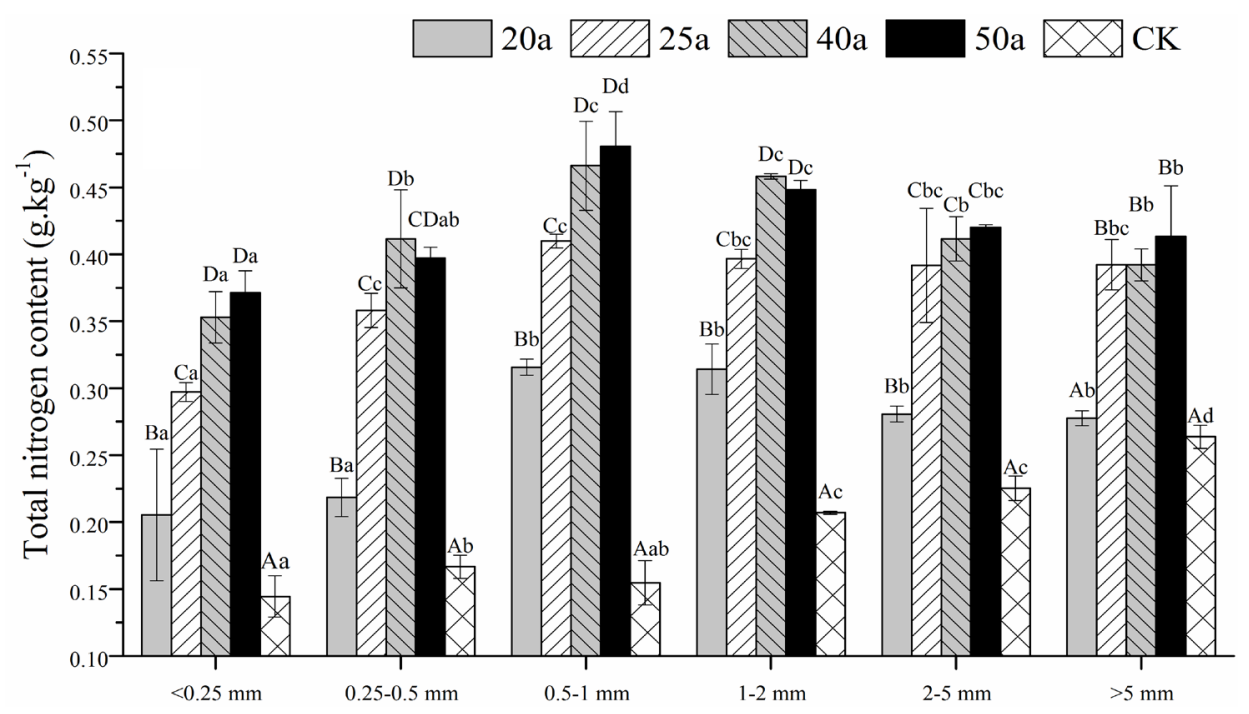

(a)

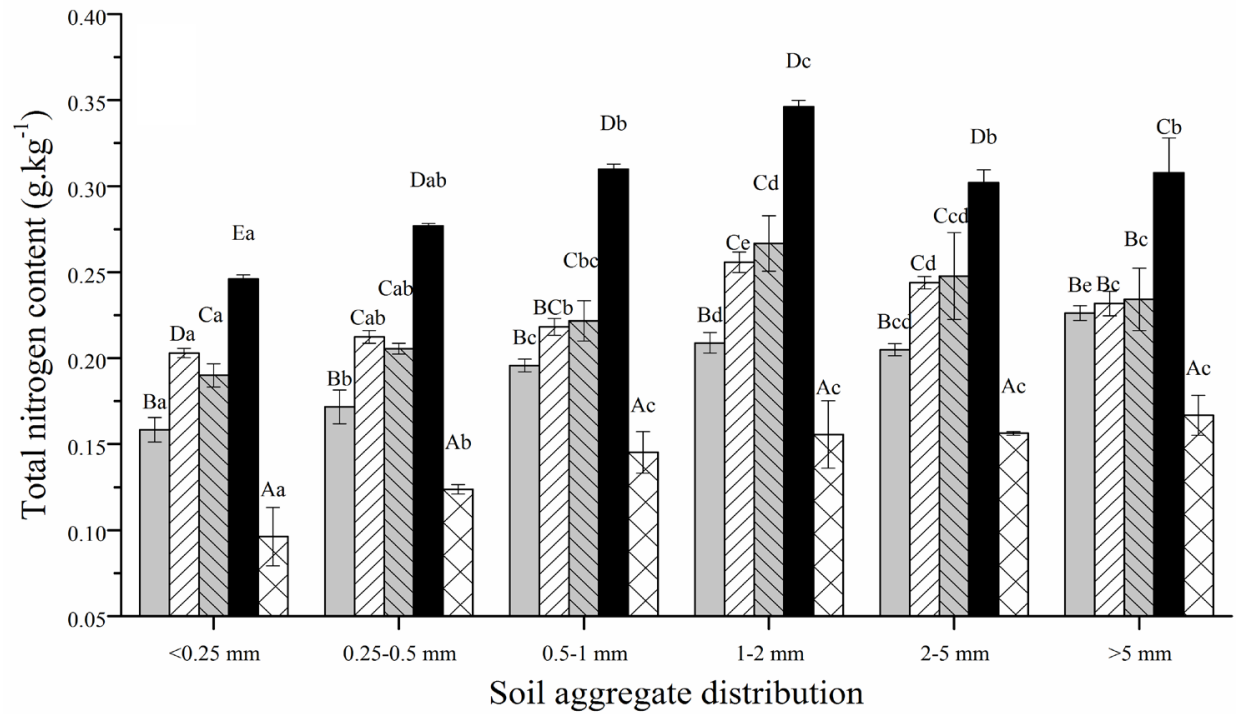

(b)

Figure 3. Concentration of total nitrogen in soil water-stable aggregates. Note: Different small letters indicate significant differences among aggregates of different sizes at the 0.05 level; different capital letters indicate significant differences among aggregates of the same size in forests of different ages at the 0.05 level. The same notation is used in subsequent figures.

As shown in Figure 2, the SOC concentrations in all WSA size fractions for Robinia pseudoacacia plantations of different ages were within the range of $0.92 \mathrm{~g}^{\mathrm{kg}} \mathrm{kg}^{-1}$ to 5.98 $\mathrm{g} \cdot \mathrm{kg}^{-1}$. The SOC concentrations in the $0-20 \mathrm{~cm}$ (Figure 2(a)) soil layers were higher than in the $20-40 \mathrm{~cm}$ (Figure 2(b)) soil layers. From the $0-20 \mathrm{~cm}$ soil layers, the SOC concentrations in all WSA size fractions tended to increase continuously along with plantation age. At the $20-40 \mathrm{~cm}$ soil layers, the SOC concentrations in all WSA size fractions were significantly higher $(P<0.05)$ in 50 a than in 40 a and in 25 a than in 20 a. However, no significant difference $(P>0.05)$ in SOC concentration was observed 


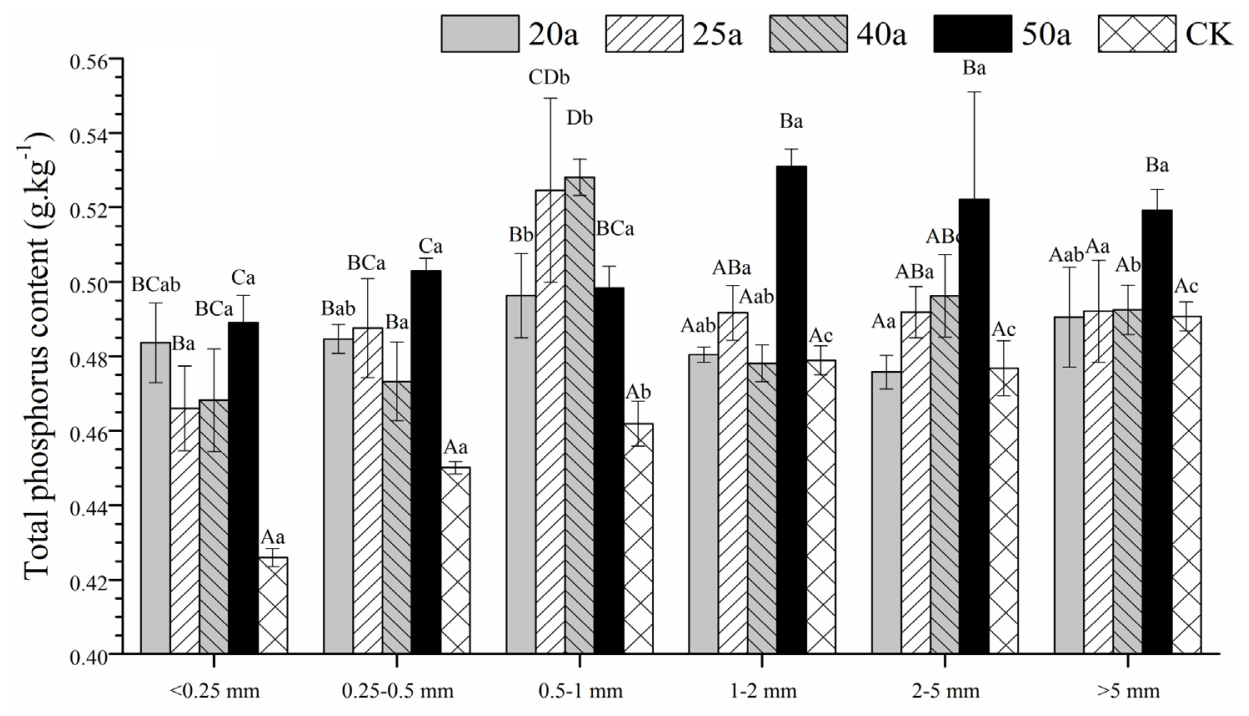

(a)

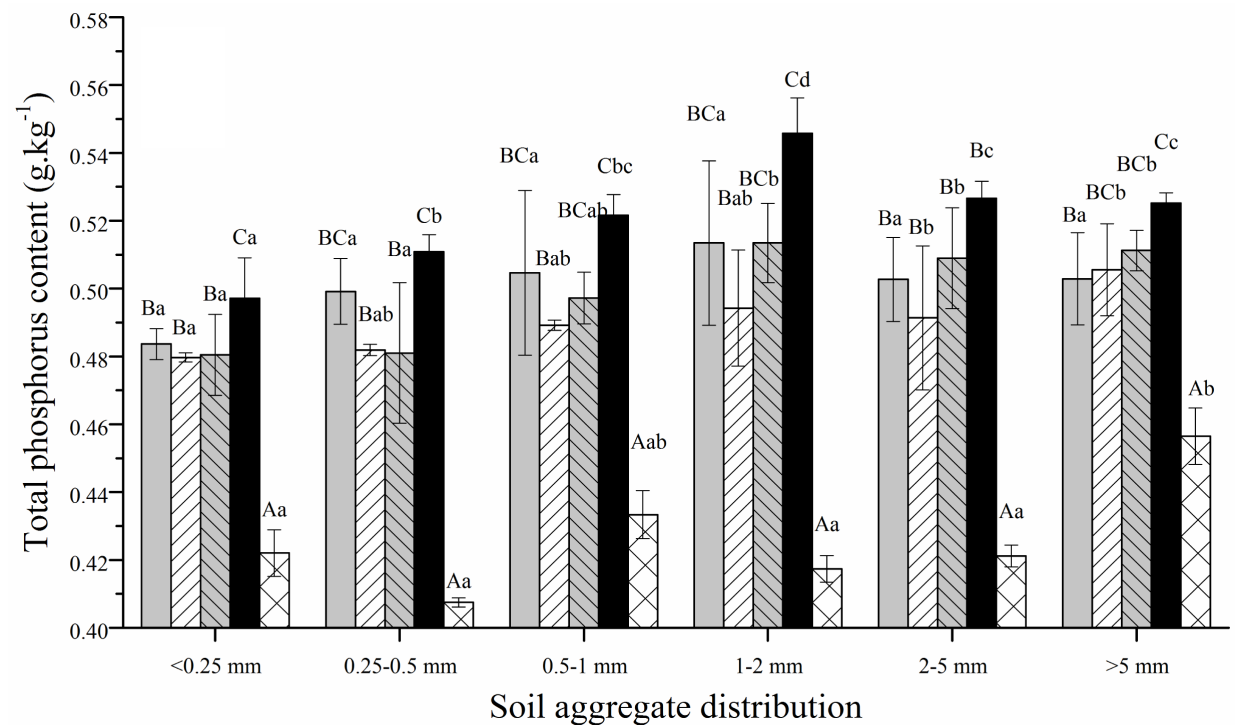

(b)

Figure 4. Concentrations of total phosphorus in soil water-stable aggregates. Note: Different small letters indicate significant differences among aggregates of different sizes at the 0.05 level; different capital letters indicate significant differences among aggregates of the same size in forests of different ages at the 0.05 level. The same notation is used in subsequent figures.

between the 25 a and 40 a groups in any WSA size fraction, the SOC concentrations in all WSA size fractions for cropland were lower than in the 20 a, 25 a, 40 a, and 50 a $R o$ binia pseudoacacia plantation groups.

The concentrations of TN in all WSA size fractions for Robinia pseudoacacia plantations of different ages at the $0-20 \mathrm{~cm}$ (Figure 3(a)) and $20-40 \mathrm{~cm}$ (Figure 3(b)) soil layers were within the range of $0.15 \mathrm{~g} \cdot \mathrm{kg}^{-1}$ to $0.48 \mathrm{~g} \cdot \mathrm{kg}^{-1}$ (Figure 3 ). The TN concentrations in WSAs at the $0-20 \mathrm{~cm}$ soil layers appeared in the following order from highest to lowest: 50 a $>40$ a $>25$ a $>20$ a $>$ cropland. No significant difference $(P>0.05)$ in the 
TN concentration of the WSAs was observed between the $40 \mathrm{a}$ and 50 a groups. In the $20-40 \mathrm{~cm}$ soil layers, TN concentrations in WSAs $>0.25 \mathrm{~mm}$ resembled those of corresponding SOC concentrations, the TN concentration in WSAs $>0.25 \mathrm{~mm}$ ranged from $0.12 \mathrm{~g} \cdot \mathrm{kg}^{-1}$ in cropland to $0.48 \mathrm{~g} \cdot \mathrm{kg}^{-1}$ in the 50 a group, and it was significantly higher $(P<0.05)$ in the 50 a group than in other Robinia pseudoacacia plantation groups $(P<0.05)$. TN concentrations in WSAs $<0.25 \mathrm{~mm}$ were in the following order from highest to lowest: 50 a $>25$ a $>40$ a $>20$ a $>$ cropland.

As shown in Figure 4, the TP concentrations in all WSA size fractions for Robinia pseudoacacia plantations of different ages were within the range of $0.47 \mathrm{~g} \cdot \mathrm{kg}^{-1}$ to 0.55 $\mathrm{g} \cdot \mathrm{kg}^{-1}$. At the $0-20 \mathrm{~cm}$ (Figure 4(a)) soil layers, the concentration of TP WSAs $>2 \mathrm{~mm}$ tended to increase along with plantation age, and it was significantly higher $(P<0.05)$ in 50 a than in the 20 a, 25 a, and 40 a groups. The concentration of TP in WSAs 0.25 $0.5 \mathrm{~mm}$ and $1-2 \mathrm{~mm}$ fraction appeared in the following order from highest to lowest: $50 \mathrm{a}>25 \mathrm{a}>20 \mathrm{a}>40 \mathrm{a}>$ cropland. In the $0.5-1 \mathrm{~mm}$ fraction, the order was as shown: $25 \mathrm{a}>20 \mathrm{a}>50 \mathrm{a}>40 \mathrm{a}>$ cropland. The concentration of TP in WSAs $<0.25 \mathrm{~mm}$ appeared in the following order: $50 \mathrm{a}>20 \mathrm{a}>40 \mathrm{a}>25 \mathrm{a}>$ cropland. In the $20-40 \mathrm{~cm}$ (Figure 4(b)) soil layers, the concentration of TP in WSA tended to increase along with plantation age in WSAs $>5 \mathrm{~mm}$. In WSAs of other sizes, the concentration was in the following order: $50 \mathrm{a}>40 \mathrm{a}>20 \mathrm{a}>25 \mathrm{a}>$ cropland.

For Robinia pseudoacacia plantations of the same age, the SOC, TN, and TP concentrations were low on both sides and high in the middle of aggregate sizes. In the $0-20$ $\mathrm{cm}$ soil layer, the highest concentrations of SOC, TN, and TP in Robinia pseudoacacia plantations was usually found in WSAs $0.5-1 \mathrm{~mm}$. This was not the case for $50 \mathrm{a}$, whose highest TP concentration was observed in WSAs $1-2 \mathrm{~mm}$ in size. In the $20-40 \mathrm{~cm}$ soil layer, the highest concentration of SOC, TN, and TP for Robinia pseudoacacia plantations was observed in WSAs $1-2 \mathrm{~mm}$ in size. The concentrations of SOC, TN, and TP in WSAs $<0.25 \mathrm{~mm}$ in the $0-20 \mathrm{~cm}$ and $20-40 \mathrm{~cm}$ soil layers were significantly lower $(P<0.05)$ than in other size fractions.

\subsubsection{Distribution of Soil Organic Carbon, Total Nitrogen, and Total Phosphorus in Soil Water-Stable Aggregates}

The contribution rates of WSAs to SOC, TN, and TP concentrations in Robinia pseudoacacia plantations of different ages in the $0-20 \mathrm{~cm}$ and $20-40 \mathrm{~cm}$ soil layers are shown in Table 4. This can indicate the relative amounts of SOC, TN, and TP in WSAs of all sizes.

The varying contribution rates of WSAs $>5 \mathrm{~mm}$ to SOC were found to depend on the ages of the Robinia pseudoacacia plantations. In the $0-20 \mathrm{~cm}$ soil layers, the contribution rates of WSAs $>5 \mathrm{~mm}$ ranged from $14.19 \%$ in the 50 a group to $34.57 \%$ in the 25 a group, and they were significantly higher $(P<0.05)$ in the 25 a group than in the $20 \mathrm{a}, 40 \mathrm{a}, 50 \mathrm{a}$, and cropland groups. The contribution rates of WSAs $>0.25 \mathrm{~mm}$ was as follows: 40 a $>25$ a $>50$ a $>20$ a $>$ cropland. The contribution rates of the $0.5-1 \mathrm{~mm}$ WSAs to the overall WSA SOC concentration tended to increases with plantation age, and the highest contribution rate of WSA $0.5-1 \mathrm{~mm}$ was observed in $50 \mathrm{a}$, which ac- 
Table 4. Contribution rates of soil water-stable aggregates to the SOC, TN and TP content

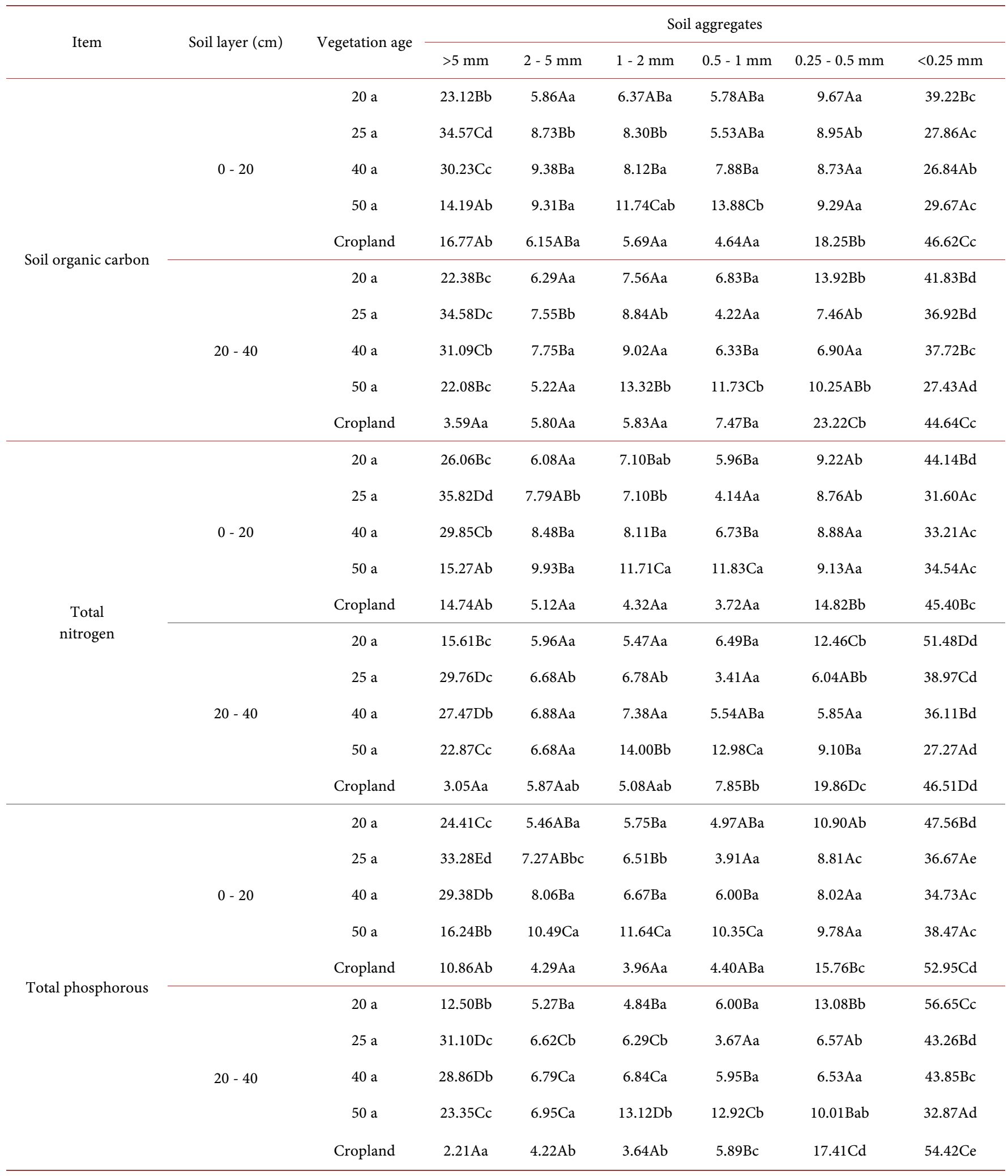

Note: Different small letters in the same row indicate significant differences among aggregates of different sizes at the 0.05 level; different capital letters in the same column indicate significant differences among aggregates of the same size in forests of different ages at the 0.05 level. The same notation is used in subsequent tables. 
counted for $15.45 \%$. In the $20-40 \mathrm{~cm}$ soil layers, the contribution rates of WSAs $>5$ $\mathrm{mm}$ to SOC were as follows: $25 \mathrm{a}>40$ a $>50 \mathrm{a}>20$ a $>$ cropland. The contribution rates of WSAs $>0.25 \mathrm{~mm}$ was as follows: $50 \mathrm{a}>25 \mathrm{a}>40 \mathrm{a}>20 \mathrm{a}>$ cropland. The contribution rates of the WSAs $1-2 \mathrm{~mm}$ in to the overall WSA SOC concentration tended to increase with plantation age, and the highest contribution rate of WSA $1-2 \mathrm{~mm}$ was observed in the 50 a group, $14.79 \%$.

The contribution rates of the WSAs from Robinia pseudoacacia plantations of different ages to TN and TP shifted in similar pattern. In the $0-20 \mathrm{~cm}$ soil layers, higher contribution rates of WSAs $>5 \mathrm{~mm}$ to TN and TP were found in the 25 a group than in the 20 a, 40 a, 50 a, or cropland groups. The contribution rates of WSAs $>0.25 \mathrm{~mm}$ were in the following order: 25 a $>40$ a $>50$ a $>20$ a $>$ cropland. For Robinia pseudoacacia plantations of different ages, the contribution rates of WSAs $0.5-2 \mathrm{~mm}$ to the overall WSA TN and TP concentrations increased continuously with plantation age. The highest contribution rates of WSAs $0.5-2 \mathrm{~mm}$ to TN and TP were observed in the 50 a group, reaching $12.80 \%$ and $12.00 \%$. In the $20-40 \mathrm{~cm}$ soil layers, the highest contribution rate of WSAs $>5 \mathrm{~mm}$ to soil TN and TP was observed in the 25 a group, while the lowest were in the $20 \mathrm{a}$, the contribution rates of WSAs $>0.25 \mathrm{~mm}$ order shifts to 50 a $>40$ a $>25$ a $>20$ a > cropland. The contribution rates of WSAs $1-2 \mathrm{~mm}$ to the overall WSA TN and TP concentrations tended to increase with plantation age.

For Robinia pseudoacacia plantations of the same age, the contribution rates of WSAs of all sizes to soil SOC, TN, and TP concentrations were similar to the distribution of WSAs. The $>5 \mathrm{~mm}$ and $<0.25 \mathrm{~mm}$ fractions always made the greatest contributions, and the sum of these fractions accounted for more than $49 \%$ of the total. The middle contribution rates of WSAs 0.25 - $5 \mathrm{~mm}$ only accounted for between $3.76 \%$ and $15.45 \%$.

\subsection{Accumulative Effect of Soil Organic Carbon, Total Nitrogen, and Total Phosphorus in Water-Stable Aggregates and Soil Stability Characteristics in Robinia pseudoacacia Plantations of Different Ages}

As shown in Table 5, linear regression models among measured soil and WSAs SOC, $\mathrm{TN}$, and TP concentrations, and distribution and stability of WSAs were determine using stepwise regression analysis.

Table 5. Stepwise regression equation of the SOC, TN and TP in water-stable aggregates and MWD.

\begin{tabular}{|c|c|c|}
\hline Items & Regression equation & $\mathrm{R}^{2}$ \\
\hline MWD and distribution of WSAs & $\mathrm{MWD}=0.061 \mathrm{WSA}_{>5 \mathrm{~mm}}+0.043 \mathrm{WSA}_{1-2 \mathrm{~mm}}+0.472$ & $0.87^{\star}$ \\
\hline MWD and SOC concentrations in WSAs & $\mathrm{MWD}=1.697 \mathrm{SOC}_{\mathrm{WSA} 2-5 \mathrm{~mm}}-1.557 \mathrm{SOC} \mathrm{WSA}_{\mathrm{W}<0.25 \mathrm{~mm}}+1.599 \mathrm{SOC}_{\mathrm{WSA} 0.25-0.5 \mathrm{~mm}}-1.297 \mathrm{SOC}_{\mathrm{WSA}>5 \mathrm{~mm}}+1.006$ & $0.85^{*}$ \\
\hline MWD and TP concentrations in WSAs & $\mathrm{MWD}=10.81 \mathrm{TP} \mathrm{WSA} 0.5-1 \mathrm{~mm}-15.321 \mathrm{TP} \mathrm{WSA}_{\mathrm{W} 0.25 \mathrm{~mm}}+4.15$ & $-0.76^{*}$ \\
\hline SOC concentrations in bulk soil and WSAs & $\mathrm{SOC}=0.17 \mathrm{SOC}_{W S A 2-5 \mathrm{~mm}}+0.534 \mathrm{SOC}_{\mathrm{WSA} 0.25-0.5 \mathrm{~mm}}+0.43 \mathrm{SOC}_{\mathrm{WSA}<0.25 \mathrm{~mm}}-0.035$ & $0.98^{\star *}$ \\
\hline TP concentrations in bulk soil and WSAs & $\mathrm{TP}=0.453 \mathrm{TP}_{\mathrm{WSA} 2-5 \mathrm{~mm}}+0.277$ & $0.60^{*}$ \\
\hline
\end{tabular}

Note: ${ }^{*} P<0.05,{ }^{* *} P<0.01$. 
Results indicated that the MWD was significantly $(P<0.05)$ and positively correlated to WSAs $>5 \mathrm{~mm}$ and $1-2 \mathrm{~mm}$. Similarly, significant and positive correlations were observed between MWD and SOC, TN concentrations in WSAs, significant $(P<0.05)$ and negative correlations were observed between MWD and TP concentrations in WSAs. The MWD was significantly $(P<0.05)$ positively correlated to the concentration of SOC in WSAs $0.25-0.5 \mathrm{~mm}$ and $2-5 \mathrm{~mm}$, and to the concentrations of TN and TP in WSAs $<0.25 \mathrm{~mm}$.

Significant positive correlations $(P<0.05)$ were observed between SOC, TN and TP concentrations in bulk soils and WSAs. Significantly and positively correlations $(P<$ $0.05)$ were obtained between SOC concentrations in bulk soils and those in WSAs $<0.5$ $\mathrm{mm}$ and $2-5 \mathrm{~mm}$. A significant positive correlation $(P<0.05)$ was obtained between TN concentrations in bulk soil and those in WSA $>5 \mathrm{~mm}, 1-2 \mathrm{~mm}$ and $<0.25 \mathrm{~mm}$. This was also a significant positive correlation $(P<0.05)$ between TP concentrations in bulk soil and WSA $2-5 \mathrm{~mm}$.

\section{Discussion}

Soil aggregate stability is an effective method of evaluating of soil structure [23]. Greater $\mathrm{R}_{0.25}$, MWD of soil WSAs can lead to higher soil aggregation and more stable soil structures [2]. $\mathrm{R}_{0.25}$ mostly tended to increase along with Robinia pseudoacacia plantation age. As plantation age increased, the plant cover, litter biomass, and plant biomass also increased, which can lead to higher soil organic matter input. This may play a key role in the formation of soil macro-aggregates [24]. Soil organic matter was found to be positively correlated with soil microbial activity and microbe-derived binding agents, which could also influence the formation of macro-aggregates [25]. However, more WSAs can be obtained by the physical enmeshment of the soil particles by fungal hyphae and roots, which tended to increase along with plantation age [26]. In this study, no significant correlation was observed between MWD and plantation age. As age increased, the MWD tended to first increase, then decrease. The highest MWD was observed in the 25 a group. Stepwise regression analysis indicated that the MWD was significantly correlated to WSAs $>5 \mathrm{~mm}$ and $1-2 \mathrm{~mm}$. This suggested that soil macroaggregates of Robinia pseudoacacia plantation tended to increase over time. At the same time, WSAs $>5 \mathrm{~mm}$ splitting into micro-aggregates and smaller macro-aggregates. In accordance with results of the current study, the stability of WSAs tended to increase with age and then plateau after rapid growth in 5 - 25 a [27]. Robinia pseudoacacia plantations entered an aging period after 50 years. Plantation productivity declined rapidly during the middle and late growth periods, leading to severe soil degradation, affecting the plantations' continued growth and soil aggregate stability. The MWD of Robinia pseudoacacia plantations of different ages was found to be positively correlated with SOC concentrations in WSAs of $0.25-0.5 \mathrm{~mm}$ and $2-5 \mathrm{~mm}$. This suggested that aggregate stability was significantly affected by SOC concentrations in soil macro-ag- gregates. Like the relationship between the MWD and TN, TP concentrations in WSAs $<0.25 \mathrm{~mm}$ were positively correlated with MWD. However, MWD was 
negatively correlated with TN in WSAs $>5 \mathrm{~mm}$ and TP in WSAs $0.5-1 \mathrm{~mm}$. This suggested that an increase in TN and TP in macro-aggregates could decrease aggregate stability. This phenomenon is caused by nitrogen in ammonium form, which has a negative influence on soil structure [28].

The distribution of WSAs was found to reflect the influence of vegetation restoration on soil quality [29]. For Robinia pseudoacacia plantations of the same age, most of the WSAs were distributed in the $>5 \mathrm{~mm}$ and $<0.25 \mathrm{~mm}$ fractions, others were found in the $0.25-5 \mathrm{~mm}$ fraction. Consistent with these results, An et al. reported that the highest proportion of WSAs was found in the $>5 \mathrm{~mm}$ and $<0.25 \mathrm{~mm}$ fractions, as indicated by Yoder's method [30]. Su et al. found that the highest proportion of WSAs was $<0.25 \mathrm{~mm}$, and then was $>5 \mathrm{~mm}$. No positive difference was observed among other size fractions [31].

In this study, SOC and TN concentrations in WSAs increased significantly with increasing age and decreased significantly with soil depth. However, TP concentrations in WSAs showed small changes. Fresh organic matter such as animal and plant residues, root secretions, metabolic products of microorganisms, and the dynamic balance of input and output were all important factors affecting soil organic matter [32]. The amount of fresh organic matter input tended to increase with plantation age. For this reason, the concentrations of SOC and TN in WSAs were significantly higher in older plantations. In addition, due to the soil surface $(0-20 \mathrm{~cm})$ received input of fresh organic matter, SOC and TN concentrations in WSAs was higher than in other soil layers. TP concentration was influenced primarily by soil parent materials. Organic matter input had a smaller input [33]. TP concentrations in WSAs of Robinia pseudoacacia plantations presented only small increasing trends as plantation age increased. In this study, the SOC and TN concentrations in WSAs were within the range of $0.92 \mathrm{mg} \cdot \mathrm{g}^{-1}$ to $5.98 \mathrm{mg} \cdot \mathrm{g}^{-1}$ and within the range of $0.15 \mathrm{mg} \cdot \mathrm{g}^{-1}$ to $0.48 \mathrm{mg} \cdot \mathrm{g}^{-1}$ for Robinia pseudoacacia plantations of different ages. This observation was below the result from Zhao et al. [26] and Ai et.al [17]. This may be because each area was affected by severe erosion, causing nutrient loss. Erosion also significantly reduced SOC and TN concentrations in WSAs [34].

With the increase of plantation age, SOC, TN, and TP concentrations in WSAs of Robinia pseudoacacia plantations presented different rates of increase. For plantations of the same age, the SOC, TN, and TP concentrations in WSAs showed a distribution opposite to that of WSAs. The highest SOC, TN, and TP concentrations in WSAs were observed in the $0.5-2 \mathrm{~mm}$ fraction, and the lowest SOC, TN, and TP concentrations in WSAs were $<0.25 \mathrm{~mm}$. This suggested that with increasing age, SOC, TN, and TP concentrations in WSAs were mainly present in macro-aggregates. Dr. Devine studied SOC concentrations in WSAs in 3 different agroecological systems and found the highest SOC concentration in WSAs to be 0.25 - $2 \mathrm{~mm}$ [35]. Macro-aggregates had higher SOC concentrations than micro-aggregates because they were composed of micro-aggregates plus additional organic matter, which bound them into macro-aggregates [36]. The formation of WSAs and aggregate stability were generally related to SOC, which resulted in a higher TN and TP concentrations in soil macro-aggregates [37]. 
Combined consideration for the distribution and SOC, TN and TP concentrations in WSAs, can not only indicate the contribution rates of WSAs to SOC, TN, and TP concentrations in detail but it can also comprehensively indicate the correlations between plantation age and soil properties [38]. In this study, the contribution rates of WSAs 0.25 - $2 \mathrm{~mm}$ to soil SOC, TN, and TP tended to increase continuously along with plantation age. As the stand of trees began to mature into a plantation, litter content increased, which increased the amounts of SOC and TN stored in WSAs. The distribution of mid-sized WSAs increased significantly as plantation age increased. This increased the contribution rates of middle-sized aggregates to soil SOC, TN, and TP concentrations with plantation age. In this study, the contribution rates of WSAs of all sizes to soil SOC, TN, and TP concentrations were similar to the distribution of WSAs. Although the SOC, TN, and TP concentrations in WSAs $>5 \mathrm{~mm}$ and $<0.25 \mathrm{~mm}$ were lower than those of WSAs with other size fractions, but the contribution of WSAs $>5$ $\mathrm{mm}$ and $<0.25 \mathrm{~mm}$ was greater. The highest contribution rates of WSAs to soil SOC, $\mathrm{TN}$, and TP were always $>5 \mathrm{~mm}$ and $<0.25 \mathrm{~mm}$ fractions. This observation was consistent with the results from $\mathrm{Li}$ and Ling et al. [39] [40]. The stepwise regression analysis of SOC, TN, and TP concentrations in WSAs indicated that the soil SOC concentration was positively correlated with SOC in WSAs $0.25-0.5 \mathrm{~mm}$, the soil TN concentration was positively correlated with TN in WSAs $<0.25 \mathrm{~mm}$, and the soil TP concentration was positively correlated with TP in WSAs $2-5 \mathrm{~mm}$.

\section{Conclusion}

The WSAs, MWD, and concentrations of SOC, TN, and TP in soil WSAs from cropland were significantly lower than those of Robinia pseudoacacia plantations at soil depths of $0-20 \mathrm{~cm}$ and $20-40 \mathrm{~cm}(\mathrm{P}<0.05)$. Older plantations showed larger WSA particles $(>0.25 \mathrm{~mm})$, but MWD tended to firstly increase, and then decrease, with plantation age. The highest MWD was observed in 25 a samples. This suggested that planting Robinia pseudoacacia can increase soil aggregate stability. The stability of the soil aggregates was positively correlated with the distribution of WSAs $>5 \mathrm{~mm}$ and 1 $2 \mathrm{~mm}$ in size, SOC concentration in WSAs $2-5 \mathrm{~mm}$ in size, and TN and TP concentrations in WSAs $<0.25 \mathrm{~mm}$ in size, while the soil aggregate stability was found to be decreased by increasing TN concentrations in WSAs $>5 \mathrm{~mm}$ and TP concentration in WSAs $0.5-1 \mathrm{~mm}$. SOC and TN concentrations in WSAs were significantly higher in older plantations, and decreased significantly with soil depth. However, TP concentrations in WSAs presented small changes. In addition, SOC in $0.25-0.5 \mathrm{~mm}$ WSAs, TN in $<0.25 \mathrm{~mm}$ and $1-2 \mathrm{~mm}$ WSAs and TP in $2-5 \mathrm{~mm}$ WSAs were dominant independent variables affecting SOC, TN, and TP concentrations in bulk soils. However, the highest contribution rates in WSAs to soil SOC, TN, and TP concentrations were observed in $<0.25 \mathrm{~mm}$ fractions. Altogether, planting Robinia pseudoacacia in the loess hilly region of Shaanxi Province significantly increased the number and stability of macro-aggregates and the accumulation of SOC, TN, and TP in aggregates of all sizes. 


\section{Acknowledgements}

We thank Dr. F.Z. Zhao and Master students P.S. Sun, J.H. He and R. Du of the Northwest Agriculture and Forest University for helping to do the field survey and lab experiments of this article. We are grateful to Dr. K.Y. Wang and Dr. H. Fan of the Shihezi University for valuable comments. We appreciate the financial support of the special fund for forest-scientific Research in the Public Interest (201304312), the National Natural Science Fund Project (U1203282, 41301601), the Applied Basic Research Programs of Science and Technology Commission Foundation of Xinjiang Bingtuan (2016AG003) and the Ph.D. Program Foundation of the Shihezi University (RCZX201527).

\section{References}

[1] Le Bissonnais, Y. (2016) Aggregate Stability and Assessment of Soil Crustability and Erodibility: I. Theory and Methodology. European Journal of Soil Science, 67, 11-21.

https://doi.org/10.1111/ejss.4 12311

[2] Bronick, C.J. and Lal, R. (2005) Soil Structure and Management: A Review. Geoderma, 124, 3-22. https://doi.org/10.1016/j.geoderma.2004.03.005

[3] Guggenberger, G., Zech, W. and Thomas, R.J. (1995) Lignin and Carbohydrate Alteration in Particle-Size Separates of an Oxisol under Tropical Pastures following Native Savanna. Soil Biology and Biochemistry, 27, 1629-1638. https://doi.org/10.1016/0038-0717(95)00080-X

[4] Xia, J.Q., Zhang, M.K. and Xu, J.M. (2005) Effects of the Reclamation of Forest Land on Organic Carbon, Nitrogen and Phosphorus Pools in Red Soils of Different Texturel. Chinese Journal of Soil Science, 2, 185-205. (In Chinese with English abstract)

[5] Wright, A.L. and Hons, F.M. (2005) Carbon and Nitrogen Sequestration and Soil Aggregation under Sorghum Cropping Sequences. Biology and Fertility of Soils, 41, 95-100. https://doi.org/10.1007/s00374-004-0819-2

[6] Geng, R.L., Yu, H.-Y., Ding, W.X. and Cai, Z.C. (2010) Effects of Long-Term Application of Organic Manure and Chemical Fertilizers on Organic Carbon in Aggregates of a Sandy Loam. Soils, 42, 908-914. (In Chinese with English abstract)

[7] Wang, Y., Yang, Z.-M. and Shen, Q.-R. (2000) Distribution of C, N, P and K in Different Particle Size Fractions of Soil and Availability of N in Each Fraction. Acta Pedologica Sinica, 37, 85-94.

[8] Keming, F.B.C.L.M. (1999) The Effect of Land Use Change on the Regional Environmental in the Yangjuangou Catchment in the Loess Plateau of China. Acta Geographica Sinica, 54, 241-246. (In Chinese with English abstract)

[9] Cao, S., Chen, L., Xu, C. and Liu, Z. (2007) Impact of Three Soil Types on Afforestation in China's Loess Plateau: Growth and Survival of Six Tree Species and Their Effects on Soil Properties. Landscape and Urban Planning, 83, 208-217. https://doi.org/10.1016/j.landurbplan.2007.04.006

[10] Zheng, F.-L. (2006) Effect of Vegetation Changes on Soil Erosion on the Loess Plateau. Pedosphere, 16, 420-427. https://doi.org/10.1016/s1002-0160(06)60071-4

[11] Stokes, A., Sotir, R., Chen, W. and Ghestem, M. (2010) Soil Bio- and Eco-Engineering in China: Past Experience and Future Priorities. Ecological Engineering, 36, 247-257. https://doi.org/10.1016/j.ecoleng.2009.07.008 
[12] Sitzia, T., Campagnaro, T., Dainese, M. and Cierjacks, A. (2012) Plant Species Diversity in Alien Black Locust Stands: A Paired Comparison with Native Stands across a North-Mediterranean Range Expansion. Forest Ecology and Management, 285, 85-91. https://doi.org/10.1016/j.foreco.2012.08.016

[13] Degomez, T. and Wagner, M. (2001) Arthropod Diversity of Exotic vs. Native Robinia Species in Northern Arizona. Agricultural and Forest Entomology, 3, 19-27.

https://doi.org/10.1046/j.1461-9563.2001.00082.x

[14] Cierjacks, A., Kowarik, I., Joshi, J., Hempel, S., Ristow, M., der Lippe, M. and Weber, E. (2013) Biological Flora of the British Isles: Robinia pseudoacacia. Journal of Ecology, 101, 1623-1640. https://doi.org/10.1111/1365-2745.12162

[15] Zhang, S., Wang, G. and Tian, P. (2004) Distributive Feature of Soil Microorganism of Robinia pseudoacacia L. Plantation Forestland in Loess Plateau. Journal of Soil and Water Conservation, 18, 128-131.

[16] Zhang, X.R., Ma, L.S., Chen, Y.N. and Yang, J.J. (2013) Ecological Stoichiometry Characteristics of Robinia pseudoacasia Forest Soil in Different Latitudes of Loess Plateau. Acta Pedologica Sinica, 50, 182-189.

[17] Ai, Z., Chen, Y.M. and Cao, Y. (2014) Storage and Allocation of Carbon and Nitrogen in Robinia pseudoacacia Plantation at Different Ages in the Loess Hilly Region, China. Chinese Journal of Applied Ecology, 25, 333-341. (In Chinese with English abstract)

[18] Han, X., Tong, X., Yang, G., Xue, Y. and Zhao, F. (2012) Difference Analysis of Soil Organic Carbon Pool in Returning Farmland to Forest in Loess Hilly Area. Transactions of the Chinese Society of Agricultural Engineering, 28, 223-229.

[19] Dickson, E., Rasiah, V. and Groenevelt, P. (1991) Comparison of Four Prewetting Techniques in Wet Aggregate Stability Determination. Canadian Journal of Soil Science, 71, 6772. https://doi.org/10.4141/cjss91-006

[20] Han, F., Ren, L. and Zhang, X. (2016) Effect of Biochar on the Soil Nutrients about Different Grasslands in the Loess Plateau. CATENA, 137, 554-562.

https://doi.org/10.1016/j.catena.2015.11.002

[21] Shirazi, M.A. and Boersma, L. (1984) A Unifying Quantitative Analysis of Soil Texture. Soil Science Society of America Journal, 48, 142-147. https://doi.org/10.2136/sssaj1984.03615995004800010026x

[22] Onweremadu, E., Onyia, V. and Anikwe, M. (2007) Carbon and Nitrogen Distribution in Water-Stable Aggregates under Two Tillage Techniques in Fluvisols of Owerri Area, Southeastern Nigeria. Soil and Tillage Research, 97, 195-206. https://doi.org/10.1016/j.still.2007.09.011

[23] Yamashita, T., Flessa, H., John, B., Helfrich, M. and Ludwig, B. (2006) Organic Matter in Density Fractions of Water-Stable Aggregates in Silty Soils: Effect of Land Use. Soil Biology and Biochemistry, 38, 3222-3234. https://doi.org/10.1016/j.soilbio.2006.04.013

[24] Cambardella, C. and Elliott, E. (1992) Particulate Soil Organic-Matter Changes across a Grassland Cultivation Sequence. Soil Science Society of America Journal, 56, 777-783. https://doi.org/10.2136/sssaj1992.03615995005600030017x

[25] Six, J., Elliott, E. and Paustian, K. (1999) Aggregate and Soil Organic Matter Dynamics under Conventional and No-Tillage Systems. Soil Science Society of America Journal, 63, 1350-1358. https://doi.org/10.2136/sssaj1999.6351350x

[26] Zhao, X., Li, J. and Li, H. (2010) Effects of Vegetation Restoration Type on Soil Carbon, Nitrogen, and Microbial Quantity in Guandi Mountain. Chinese Journal of Ecology, 29, 2102-2110. (In Chinese with English abstract) 
[27] Zhang, C., Liu, G.B., Xue, S. and Yu, N. (2010) Evolution of Soil Anti-Erodiblity of Robinia pseudoacacia L. Plantation at Different Ages in Hilly-Gully Region of Loess Plateau. Science of Soil and Water Conservation, 8, 1-7.

[28] Haynes, R. and Naidu, R. (1998) Influence of Lime, Fertilizer and Manure Applications on Soil Organic Matter Content and Soil Physical Conditions: A Review. Nutrient Cycling in Agroecosystems, 51, 123-137. https://doi.org/10.1023/A:1009738307837

[29] Madari, B., Machado, P.L., Torres, E., de Andrade, A.G. and Valencia, L.I. (2005) No Tillage and Crop Rotation Effects on Soil Aggregation and Organic Carbon in a Rhodic Ferralsol from Southern Brazil. Soil and Tillage Research, 80, 185-200.

https://doi.org/10.1016/j.still.2004.03.006

[30] An, S.-S., Darboux, F. and Cheng, M. (2013) Revegetation as an Efficient Means of Increasing Soil Aggregate Stability on the Loess Plateau (China). Geoderma, 209, 75-85. https://doi.org/10.1016/j.geoderma.2013.05.020

[31] Su, J. and Zhao, S.-W. (2009) Comparison of the Analysis Methods for Soil Aggregate Stability. Bulletin of Soil and Water Conservation, 5, 028.

[32] Grandy, A.S. and Neff, J.C. (2008) Molecular C Dynamics Downstream: The Biochemical Decomposition Sequence and Its Impact on Soil Organic Matter Structure and Function. Science of the Total Environment, 404, 297-307.

https://doi.org/10.1016/j.scitotenv.2007.11.013

[33] Liu, X.Z., Zhou, G.Y., Zhang, D.Q., Liu, S.Z., Chu, G.W., Yan, J. H., He, J.S. and Han, X.G. (2010) N and P Stoichiometry of Plant and Soil in Lower Subtropical Forest Successional Series in Southern China. Journal of Plant Ecology (Chinese Version), 34, 64-71.

[34] Yang, J., An, S. and Zhang, F. (2006) Characteristics of Soil Water Stable Aggregates and Relationship with Soil Properties during Vegetation Rehabilitation in Ningxia Loess Hilly Region. Journal of Soil and Water Conservation, 20, 72-75.

[35] Devine, S., Markewitz, D., Hendrix, P. and Coleman, D. (2014) Soil Aggregates and Associated Organic Matter under Conventional Tillage, No-Tillage, and Forest Succession after Three Decades. PLOS ONE, 9, e84988. https://doi.org/10.1371/journal.pone.0084988

[36] Elliott, E. (1986) Aggregate Structure and Carbon, Nitrogen, and Phosphorus in Native and Cultivated Soils. Soil Science Society of America Journal, 50, 627-633. https://doi.org/10.2136/sssaj1986.03615995005000030017x

[37] Puget, P., Chenu, C. and Balesdent, J. (2000) Dynamics of Soil Organic Matter Associated with Particle-Size Fractions of Water-Stable Aggregates. European Journal of Soil Science, 51, 595-605. https://doi.org/10.1111/j.1365-2389.2000.00353.x

[38] Qiu, L.P., Zhang, X.C. and Zhang, J.A. (2006) Distribution of Nutrients and Enzymes in Loess Plateau Soil Aggregates after Long-Term Fertilization. Acta Ecologica Sinica, 26, 364372.

[39] Lu, L.X., Song, T.Q., Peng, W.X., Zeng, F.P., Wang, K.L., Xu, Y.L., Yu, Z. and Liu, Y. (2012) Profile Distribution of Soil Aggregates Organic Carbon in Primary Forests in Karst Cluster-Peak Depression Region. Chinese Journal of Applied Ecology, 23, 1167-1174. (In Chinese with English abstract)

[40] Li, W., Zheng, Z., Li, T., Zhang, X., Wang, Y., Yu, H., He, S. and Liu, T. (2015) Effect of Tea Plantation Age on the Distribution of Soil Organic Carbon Fractions within Water-Stable Aggregates in the Hilly Region of Western Sichuan, China. CATENA, 133, 198-205. https://doi.org/10.1016/j.catena.2015.05.017 
Submit or recommend next manuscript to SCIRP and we will provide best service for you:

Accepting pre-submission inquiries through Email, Facebook, LinkedIn, Twitter, etc. A wide selection of journals (inclusive of 9 subjects, more than 200 journals)

Providing 24-hour high-quality service

User-friendly online submission system

Fair and swift peer-review system

Efficient typesetting and proofreading procedure

Display of the result of downloads and visits, as well as the number of cited articles

Maximum dissemination of your research work

Submit your manuscript at: http://papersubmission.scirp.org/

Or contact ojss@scirp.org 